\title{
The MHC and non-random mating in a captive population of Chinook salmon
}

\author{
BD Neff ${ }^{1}$, SR Garner ${ }^{1}$, JW Heath ${ }^{2}$ and DD Heath ${ }^{3}$ \\ ${ }^{1}$ Department of Biology, University of Western Ontario, London, Ontario, Canada; ${ }^{2} Y e l l o w ~ I s l a n d ~ A q u a c u l t u r e ~ L t d$, Campbell River, \\ British Columbia, Canada and ${ }^{3}$ Great Lakes Institute for Environmental Research and the Department of Biological Sciences, University \\ of Windsor, Windsor, Ontario, Canada
}

\begin{abstract}
Detailed analysis of variation in reproductive success can provide an understanding of the selective pressures that drive the evolution of adaptations. Here, we use experimental spawning channels to assess phenotypic and genotypic correlates of reproductive success in Chinook salmon (Oncorhynchus tshawytscha). Groups of 36 fish in three different sex ratios $(1: 2,1: 1$ and $2: 1)$ were allowed to spawn and the offspring were collected after emergence from the gravel. Microsatellite genetic markers were used to assign parentage of each offspring, and the parents were also typed at the major histocompatibility class IIB locus (MHC). We found that large males, and males with brighter coloration and a more green/blue hue on their lateral integument sired more offspring, albeit only body size and brightness had indepen-
\end{abstract}

dent effects. There was no similar relationship between these variables and female reproductive success. Furthermore, there was no effect of sex ratio on the strength or significance of any of the correlations. Females mated non-randomly at the $\mathrm{MHC}$, appearing to select mates that produced offspring with greater genetic diversity as measured by amino-acid divergence. Females mated randomly with respect to male genetic relatedness and males mated randomly with respect to both $\mathrm{MHC}$ and genetic relatedness. These results indicate that sexual selection favours increased body size and perhaps integument coloration in males as well as increases genetic diversity at the MHC by female mate choice.

Heredity (2008) 101, 175-185; doi:10.1038/hdy.2008.43; published online 28 May 2008

Keywords: salmon; major histocompatibility complex; reproductive success; mate choice; sexual selection; fitness

\section{Introduction}

Understanding variation in reproductive success among individuals is a key objective of evolutionary ecology and the cornerstone of sexual selection. Sexual selection involves intra-sexual selection, such as male-male competition, and inter-sexual selection or mate choice (Andersson, 1994). With the proliferation of molecular techniques, it is now possible to partition variation in reproductive success, and hence the outcome of sexual selection, to phenotypic and genotypic effects. For example, male-male competition may favour phenotypes that increase dominance or competitive ability such as large body size (Fleming and Gross, 1993) and weaponry like the antlers in male cervids (Clutton-Brock, 1982). Mate choice, on the other hand, can select for genetic benefits including 'good genes' that show additive genetic variance and 'compatible genes' that show non-additive genetic variance (Neff and Pitcher, 2005). For example, female gray tree frogs prefer to mate with males that have long courtship calls and the offspring of long-calling males consistently have higher fitness than those of short-calling males, which suggests

Correspondence: Professor BD Neff, Department of Biology, University of Western Ontario, 1151 Richmond Street, London, Ontario, Canada N6A $5 B 7$.

E-mail: bneff@uwo.ca

Received 7 February 2008; revised 14 April 2008; accepted 18 April 2008; published online 28 May 2008 an additive genetic effect (Klump and Gerhardt, 1987; Welch et al., 1998). Mate choice for compatible genes has largely focused on inbreeding avoidance and disassortative mating at the immune loci of the major histocompatibility complex (MHC; reviewed by Mays and Hill, 2004). In the present study, we partition variation in reproductive success to body size and coloration (phenotype) and diversity at the MHC (genotype) in Chinook salmon (Oncorhynchus tshawytscha).

The genes of the MHC encode proteins that are important in the immune response of vertebrates. MHC proteins (class I and II) work by binding fragments of foreign peptides and then presenting these peptides on the cell surface to $\mathrm{T}$ cells, which initiate an immune response (Janeway et al., 1999; Bernatchez and Landry, 2003). Class I MHC proteins are expressed on all nucleated somatic cells, and generally recognize intracellular pathogens such as viruses. Class II MHC proteins are expressed on antigen-presenting immune cells that include B cells and macrophages, which primarily recognize extracellular pathogens such as parasites and some bacteria (Janeway et al., 1999). The amino-acid sequence of the MHC molecule, particularly at the peptide-binding region, determines which antigens can be bound, and hence which pathogens can be recognized (Brown et al., 1988). Thus, diversity at the MHC locus should allow an individual to respond to a greater range of pathogens (Doherty and Zinkernagel, 1975).

There has been considerable research on mate choice and MHC diversity (for reviews see Penn, 2002; 
Bernatchez and Landry, 2003; Ziegler et al., 2005). Perhaps best studied in mice (Mus musculus), numerous studies have shown that females prefer to mate with males that differ from their own MHC genotype, presumably to produce offspring that are diverse at the MHC (Potts et al., 1991; Penn and Potts, 1998; Roberts and Gosling, 2003). Indeed, one study showed that MHC heterozygous mice were more likely to clear Salmonella infections, weighed more and had higher survivorship than MHC homozygous mice (Penn et al., 2002). Interestingly, it has also been shown in mice that peptide ligands of MHC molecules activate vomeronasal organ sensory neurons, which confirms that there is a mechanism by which female mice can evaluate MHC genotype (Leinders-Zufall et al., 2004). In Savannah sparrows (Passerculus sandwichensis), females paired to social mates that were similar to themselves at the MHC class IIB gene were more likely to seek extra-pair mates (FreemanGallant et al., 2003). Yet other studies have suggested that there can be an optimal level of diversity at the MHC. For example, in three-spined sticklebacks (Gasterosteus aculeatus), which are characterized by gene replication at the MHC class IIB, individuals with an intermediate number of alleles showed greater resistance when challenged by multiple pathogens (Kurtz et al., 2004). Furthermore, female three-spined sticklebacks appear to select mates such that their offspring have the optimal number of MHC alleles (Reusch et al., 2001). Similarly, in brown trout (Salmo trutta), females but not males appear to select mates that are of intermediate MHC dissimilarity to themselves (Forsberg et al., 2007).

The Pacific salmon (Oncorhynchus spp.) provide ideal mating systems to examine variation in reproductive success. These fishes are anadromous, living part of their life in the ocean and returning to breed in freshwater streams before dying (Fleming, 1998). Because Pacific salmon are semelparous, it is relatively easy to assess lifetime reproductive success (Fleming et al., 2000; Seamons et al., 2007). Most research on the reproductive success of salmon has emphasized the importance of adult body size. Larger females can produce more and larger eggs (Beacham and Murray, 1993; Heath et al., 2003), obtain and defend high-quality nesting sites (Foote, 1990; Fleming and Gross, 1993) and bury their eggs deeper thus reducing the chance of nest superimposition (Steen and Quinn, 1999). Larger males can partake in more spawning events and obtain a superior position in spawning hierarchies (Fleming and Gross, 1993, 1994; Dickerson et al., 2002). More recently, however, researchers studying other salmonids have begun to assess genetic correlates of reproductive success including the genes of the MHC (Landry et al., 2001; Skarstein et al., 2005; Forsberg et al., 2007; also see Pitcher and Neff, 2006).

Here we study Chinook salmon and although the genes of the MHC are some of the most polymorphic loci observed in vertebrates (Bernatchez and Landry, 2003), populations of Chinook salmon are typically characterized by relatively low diversity at the MHC class II locus, with previous studies finding only 3-6 alleles per population (Miller and Withler, 1996; Kim et al., 1999; Docker and Heath, 2002; Pitcher and Neff, 2006). Despite the apparent limited MHC variability, one study showed that Chinook salmon that were heterozygous at the MHC displayed higher pathogen resistance (Arkush et al.,
2002). Specifically, Arkush et al. (2002) exposed fry from families with different MHC genotypes to one of three pathogens: a bacteria that causes vibriosis (Listonella (Vibrio) anguillarum), a myxozoan that causes whirling disease (Myxobolus cerebralis) or a virus (infectious hematopoietic necrosis virus (IHNV)). IHNV is considered one of the most important viral pathogens affecting North American salmonids (Wolf, 1988). No difference in survival between MHC homozygous and heterozygous families was observed following exposure to the bacteria or myxozoan pathogens, but MHC heterozygous families had significantly higher survival following exposure to IHNV. In contrast, studies in Atlantic salmon (S. salar) have found that specific MHC class II alleles, rather than overall MHC heterozygosity, were associated with resistance to a bacteria (Aeromonas salmonicida) that causes furunculosis (Langefors et al., 2001; Lohm et al., 2002; Grimholt et al., 2003). Another study of Chinook salmon detected a similar effect of specific MHC alleles as well as specific genotypes on survival and thereby provided evidence of both additive and non-additive effects (Pitcher and Neff, 2006). Thus, despite low variability compared to other taxa, there is growing evidence that MHC genotype has strong fitness consequences in salmonids and specifically Chinook salmon.

In the current study we used experimental spawning channels to investigate the phenotypic and genetic correlates of reproductive success in Chinook salmon. Specifically, we examined correlations between body size and coloration on reproductive success for males and females under three different sex ratios. We also examined the correlations between reproductive success and MHC diversity and multi-locus heterozygosity (MLH). Finally, we used a Monte Carlo simulation to assess potential MHC or genetic relatedness-dependent non-random mating. These data contribute to our understanding of variation in reproductive success, and provide valuable data on sexual selection in Chinook salmon.

\section{Materials and methods}

\section{Experimental fish and set-up}

Experiments were conducted using Chinook salmon at Yellow Island Aquaculture Ltd (YIAL), Quadra Island, British Columbia, Canada. The YIAL population was founded with gametes from the Robertson Creek hatchery on Vancouver Island, and has been maintained since 1986. YIAL has eliminated the male sex chromosome through the use of hormonal sex reversal in female XX salmon. Homogametic salmon are commonly raised in aquaculture to prevent early maturation by males (Piferrer, 2001; Fitzpatrick et al., 2005). To create phenotypic males for breeding, a subset of newly hatched larvae are immersed in recirculating, oxygenated water with the androgen $17 \alpha$-methyltestosterone $\left(400 \mu \mathrm{g}^{-1}\right)$ for $2 \mathrm{~h}$ at 520 ATUs (accumulated thermal units) and for another $2 \mathrm{~h}$ at 620 ATUs (Heath et al., 2002). Homogametic $(X X)$ males grow to a similar size and mass as heterogametic $(X Y)$ males, and have similar circulating levels of testosterone and 17 $\beta$-estradiol (Heath et al., 2002). XX males also display the same range of spawning behaviours used by $X Y$ males and have similar mating success when in direct competition 
with $X Y$ males in the spawning channels used in the current study (SR Garner).

From 4 to 7 October 2004, mature fish were collected from the YIAL salt water cages and anaesthetized with buffered MS222 so they could be weighed and a small portion of the adipose fin could be removed and preserved in ethanol for genetic analyses. While anaesthetized, the left side of each fish was photographed with a digital camera next to size and colour standards. These images were used to determine morphological measures consisting of total length, height measured at the dorsal fin and height at the caudal peduncle. These three measurements along with mass were collapsed into a single index using principle components analysis (the first axis had positive loadings on all four variables and captured more than $87 \%$ of the variation for both males and females). Colour was measured using Photoshop (version 7.0; Adobe) as the red, green and blue colour values averaged across all pixels within an approximately $15 \mathrm{~cm}^{2}$ area on the midline of the fish, anterior to the dorsal fin. These colour values were then corrected using the colour standards (Villafuerte and Negro, 1998) and combined into two indices with a principle components analysis. The first index captured 75\% of the variation and was a measure of 'brightness' with positive loadings for all three colours (males: red $=0.46$, green $=0.63$, blue $=0.63$; females: red $=0.36$, green $=0.66$, blue $=0.67$ ). The second index captured an additional $22 \%$ of the variation and had variable loadings among the colours (males: red $=0.89$, green-0.34 , blue $=-0.31$; females: red $=0.93$, green $=-0.22$, blue $=-0.28)$; the second axis largely measured 'hue' with negative values representing a green/blue hue and positive values representing a red hue.

The fish were then transferred to four freshwater spawning channels. Each channel received 36 fish in one of three sex ratios: 2:1 males to females $(n=1), 1: 1$ males to females $(n=1)$ and 1:2 males to females $(n=2)$. Mature females were all 4 years old, whereas males included equal numbers of 3- and 4-year-old fish in each channel. Each channel was $15 \times 3.5 \mathrm{~m}$ in size, with a water depth of approximately $1 \mathrm{~m}$, and a partially recirculating flow of approximately $3001 \mathrm{~min}^{-1}$. The gravel composition was similar to wild streams in the area and measured approximately $3-6 \mathrm{~cm}$ in diameter. The channel was located outside, and was thus exposed to natural patterns of light and temperature. The channels were surrounded on all sides by netting to exclude predators. The fish were allowed to spawn without interference, but were removed from the channel when they died. Fry from each channel were collected by seine net on 30 March 2005 and euthanized with an overdose of MS222 and frozen for later genetic analysis.

\section{Microsatellite and $M H C$ genotypes}

DNA was extracted from parents and offspring using a proteinase $\mathrm{K}$ digestion, phenol-chloroform extraction and ethanol precipitation method (Neff et al., 2000). Genetic variation was then evaluated using seven previously described microsatellite loci: Omy325, Ots3, Otsg68, Otsg78b, Otsg83b, Otsg249 and Otsg432 (Olsen et al., 1996; Williamson et al., 2002). Each forward primer was tagged with a fluorescent dye, which enabled the amplified products to be compared against size standards using an automated DNA analyzer (LI-COR Biosciences, Lincoln, NE, USA). Parental allocation was based on maximum likelihood procedures implemented in the program CERVUS version 3.0 (Marshall et al., 1998; Kalinowski et al., 2007). Because of missing genotype information in some individuals, only offspring with genotypes at four or more loci were included in the analysis. Individual reproductive success was calculated using the sum of offspring assigned to either a parental pair $(n=399$ offspring) or a single parent $(n=80$ offspring) at $80 \%$ or higher confidence (that is, a total of 479 offspring were successfully assigned to at least one parent). The breakdown of these assignments by sex ratio and channel consisted of 136 offspring from the 2:1 male to female sex ratio channel, 51 from the 1:1 sex ratio channel and 162 and 130 from the two 1:2 sex ratio channels. Analysis of mating patterns utilized only offspring for which the parental pair was assigned.

MHC genotypes were determined using a combination of a restriction enzyme assay developed for Chinook salmon from the YIAL population (Docker and Heath, 2002), single-strand conformational polymorphism (SSCP) and cloning and sequencing. Briefly, a $294 \mathrm{bp}$ portion of the MHC class IIB gene including the peptidebinding region was amplified by polymerase chain reaction (PCR). The PCR product was then digested with DdeI or RsaI and the fragments separated by electrophoresis on high-resolution agarose gel (SigmaAldrich, St Louis, MO, USA). This assay unambiguously identifies two of the primary alleles in the population, which are about $50 \%$ common overall. For ambiguous genotypes, the individuals were then analyzed with SSCP (Amersham Biosciences, Piscataway, NJ, USA) and unique banding patterns were cloned and sequenced to identify the alleles (Table 1). Any sequence appearing in only a single individual was re-cloned to ensure that it was not the result of a PCR or sequencing error. Chinook salmon have only one MHC class IIB locus and, although in mammals the two classes of MHC are inherited in a single linked genetic group, in salmon and other teleost fishes the class I and II MHC genes are inherited independently (Hansen et al., 1999).

\section{Non-random mating for genetic diversity}

We used a Monte Carlo simulation (Manly, 1997) to examine potential non-random mating at the MHC and genome-wide genetic diversity as measured by relatedness. Our null hypothesis was that males and females select mates randomly with respect to MHC diversity, amino-acid divergence (that is, mean pairwise aminoacid differences expected in offspring; see Landry et al., 2001) or genetic relatedness (Queller and Goodnight, 1989). The simulation randomly assigned mates within each channel to either males or females based on their observed number of mates. Incorporating the skew in reproductive success among mates, we calculated the mean relatedness of mates, the expected offspring MHC heterozygosity and the MHC amino-acid divergence assuming Mendelian segregation patterns. The routine was repeated for a total of 5000 simulations. The values were then sorted and the observed values from the actual data were compared to the distributions to determine $P$-values. 
Table 1 MHC class IIB alleles identified in YIAL Chinook salmon (Oncorhynchus tshawytscha)

\begin{tabular}{|c|c|c|c|c|c|c|c|c|c|c|c|c|c|c|c|c|c|c|c|c|c|c|}
\hline \multirow[t]{2}{*}{ Allele } & \multirow[t]{2}{*}{ Freq. } & \multicolumn{21}{|c|}{ Polymorphic nucleotide site } \\
\hline & & 16 & 26 & 38 & 43 & 49 & 59 & 90 & 92 & 93 & 97 & 101 & 102 & 109 & 112 & 132 & 147 & 163 & 174 & 175 & 187 & 189 \\
\hline a & 0.140 & G & $\mathrm{T}$ & $\mathrm{C}$ & $\mathrm{T}$ & A & G & G & $\mathrm{T}$ & G & G & A & G & G & G & G & G & $\mathrm{T}$ & $\mathrm{T}$ & A & $\mathrm{C}$ & $\mathrm{C}$ \\
\hline $\mathrm{b}$ & 0.113 & $\bullet$ & $\bullet$ & $\mathrm{T}$ & A & $\bullet$ & $\bullet$ & $\bullet$ & $\bullet$ & $\bullet$ & $\bullet$ & • & • & $\bullet$ & $\bullet$ & $\bullet$ & $\bullet$ & • & • & $\bullet$ & • & • \\
\hline c & 0.024 & $\bullet$ & $\bullet$ & $\bullet$ & $\bullet$ & $\bullet$ & $\mathrm{T}$ & C & $\bullet$ & $\bullet$ & $\bullet$ & G & C & C & C & $\mathrm{T}$ & C & • & $\bullet$ & $\bullet$ & • & • \\
\hline d & 0.007 & $\bullet$ & $\bullet$ & $\mathrm{T}$ & A & G & $\bullet$ & A & A & $\mathrm{T}$ & $\bullet$ & $\bullet$ & $\bullet$ & $\bullet$ & $\bullet$ & $\bullet$ & $\bullet$ & $\bullet$ & $\bullet$ & $\bullet$ & $\bullet$ & • \\
\hline $\mathrm{e}$ & 0.414 & $\bullet$ & $\bullet$ & $\mathrm{T}$ & C & $\bullet$ & $\bullet$ & A & A & $\mathrm{T}$ & $\bullet$ & $\bullet$ & • & $\bullet$ & • & • & • & • & • & $\bullet$ & • & $\bullet$ \\
\hline $\mathrm{f}$ & 0.031 & $\bullet$ & $\bullet$ & $\mathrm{T}$ & A & • & • & $\bullet$ & $\bullet$ & • & • & • & • & • & $\bullet$ & • & • & • & • & G & • & • \\
\hline g & 0.164 & C & $\bullet$ & $\mathrm{T}$ & C & $\bullet$ & • & $\bullet$ & $\bullet$ & • & C & • & • & • & $\bullet$ & • & • & G & $\bullet$ & $\bullet$ & G & G \\
\hline $\mathrm{h}$ & 0.024 & C & $\bullet$ & $\mathrm{T}$ & A & $\bullet$ & $\bullet$ & $\bullet$ & $\bullet$ & $\bullet$ & $\bullet$ & • & $\bullet$ & $\bullet$ & $\bullet$ & $\bullet$ & $\bullet$ & $\bullet$ & • & $\bullet$ & $\bullet$ & $\bullet$ \\
\hline $\mathrm{i}$ & 0.021 & C & $\bullet$ & $\mathrm{T}$ & C & $\bullet$ & $\bullet$ & $\bullet$ & $\bullet$ & $\bullet$ & $\bullet$ & $\bullet$ & • & • & $\bullet$ & $\bullet$ & $\bullet$ & $\bullet$ & $\bullet$ & $\bullet$ & $\bullet$ & $\bullet$ \\
\hline $\mathrm{j}$ & 0.027 & $\bullet$ & $\bullet$ & $\mathrm{T}$ & A & $\bullet$ & $\bullet$ & • & • & $\bullet$ & • & • & • & $\bullet$ & $\bullet$ & $\bullet$ & • & G & • & • & G & G \\
\hline $\mathrm{k}$ & 0.031 & $\bullet$ & $\bullet$ & $\bullet$ & $\bullet$ & $\bullet$ & $\bullet$ & • & • & • & • & • & $\bullet$ & $\bullet$ & $\bullet$ & • & • & • & C & $\bullet$ & • & • \\
\hline 1 & 0.003 & • & C & $\mathrm{T}$ & A & $\bullet$ & $\bullet$ & $\bullet$ & $\bullet$ & $\bullet$ & $\bullet$ & $\bullet$ & • & • & $\bullet$ & $\bullet$ & • & • & $\bullet$ & $\bullet$ & • & • \\
\hline
\end{tabular}

Allele name, frequency in the adults and sequence at 21 polymorphic nucleotide sites in the peptide-binding region are presented. Freq, frequency among breeding adults; sites that are unchanged with respect to the reference sequence are marked by a ' $\bullet$ '; complete sequences are available through GenBank (accession numbers EU627615-EU627626).

Analyses used analyses of covariance (ANCOVAs) and non-parametric statistics because some of the parameters deviated from a normal distribution. These analyses were performed using JMP version 4.0.4 (SAS Institute Inc, Cary, NC, USA). Means are reported \pm 1 standard deviation.

\section{Results}

The males used in the experiments ranged in size with a mean mass of $3.1 \pm 1.6 \mathrm{~kg}$ (s.d.) (range: $1.1-5.8 \mathrm{~kg}$ ), length of $63 \pm 11 \mathrm{~cm}$ (range: $47.4-79.4 \mathrm{~cm}$ ), height of $14.8 \pm 2.6 \mathrm{~cm}$ (range: 10.4-19.2 cm) and caudal peduncle depth of $4.7 \pm 0.7 \mathrm{~cm}$ (range: $3.5-6.1 \mathrm{~cm}$ ). The females ranged in size with a mean mass of $3.8 \pm 0.7 \mathrm{~kg}$ (range: $2.6-5.4 \mathrm{~kg}$ ), length of $69.0 \pm 4.0 \mathrm{~cm}$ (range: $61.7-78.9 \mathrm{~cm}$ ), height of $16.3 \pm 1.1 \mathrm{~cm}$ (range: $14.2-18.8 \mathrm{~cm}$ ) and caudal depth of $5.2 \pm 0.3 \mathrm{~cm}$ (range: $4.3-6.1 \mathrm{~cm}$ ). Within each sex, there was no difference in any of these size measurements among the three sex ratio treatments (ANOVAs: all $P>0.38$ ).

Initial ANCOVA analyses revealed no effect of sex ratio or its interaction with the phenotypic measures. Thus, we present only the results of the combined data set. There was considerable variation in reproductive success among both males and females (Figure 1). Across all four channels, the mean reproductive success, as calculated as a proportion of offspring analyzed from each channel, of males was 0.061 and the coefficient of variation was $0.99(n=66)$. The median number of mates for males was 2 with a range of $0-14$. For females, the mean reproductive success was 0.05 and the coefficient of variation was $1.3(n=78)$. The median number of mates for females was 2 with a range of $0-8$. For both males and females, number of mates and reproductive success were highly correlated (males: Spearman's $\rho=0.78, \quad n=66, \quad P<0.001$; females: $\rho=0.82, \quad n=78$, $P<0.001)$. Male reproductive success was positively correlated with body size (Spearman's $\rho=0.28, n=66$, $P=0.023)$ and brightness $(\rho=0.34, n=66, P=0.006)$, negatively correlated with hue $(\rho=-0.27, n=66$, $P=0.032)$ and not correlated with Fulton's condition factor $(\rho=0.21, n=66, P=0.099)$ (Figures 2 and 3). Multiple linear regression revealed effects of body size and brightness, but no independent effect of condition or hue (overall model: $r^{2}=0.30, \mathrm{~F}_{4,61}=6.69, \quad P<0.001$; Table 2). The body size effect could also be attributed to age as 3-year-old males were significantly smaller than 4-year-old males $\left(t_{64}=538, P<0.001\right)$ and had lower reproductive success $\left(t_{64}=8.62, P=0.005\right)$. There was no relationship between female reproductive success and body size (Spearman's $\rho=0.04, n=78, P=0.74$ ), Fulton's condition factor $(\rho=-0.19, n=78, P=0.093)$, brightness $(\rho=-0.08, n=78, P=0.46)$ or hue $(\rho=0.01, n=78$, $P=0.94)$ (Figures 2 and 3). Multiple linear regression provided analogous results (overall model: $r^{2}=0.05$, $\mathrm{F}_{4,77}=1.00, P=0.41$; Table 2 ). There was no relationship between these phenotypic variables and the number of mates for either males or females ( $P>0.24$ for each).

On the basis of the genetic analysis, we found $12 \mathrm{MHC}$ alleles that coded for 11 different amino-acid sequences (Table 1; Appendix 1). On the basis of the amino-acid sequences, $64 \%(42 / 66)$ of males and $74 \%(58 / 78)$ of females were heterozygous. These numbers were not significantly different $\left(\chi^{2}=1.94\right.$, d.f. $\left.=1, P=0.16\right)$. The mean MLH for males and females also did not differ (males: $0.80 \pm 0.11$; females: $0.82 \pm 0.15$; Wilcoxon $z=1.46$, $n=144, P=0.14)$. We found no relationship between either MLH or MHC heterozygosity and reproductive success in either males or females $(P>0.10$ for all). However, the Monte Carlo simulation revealed a significant departure from random mating at the MHC for females but not males (Figure 4). Females mated with males that produced offspring that had a greater divergence in MHC amino-acid sequences $(P=0.024)$ but that were not more heterozygous $(P=0.37)$ than expected by random mating. These effects at the MHC appeared independent of genetic relatedness as females mated randomly with respect to this variable $(P=0.15$; Figure 4). There was no relationship between female phenotype and MLH or MHC divergence $(P>0.11$ for each), except for brightness, which was positively correlated with MHC divergence $(\rho=0.27, n=78$, $P=0.015)$. However, this latter relationship is marginally non-significant when controlling for multiple tests (corrected $\alpha=0.0125(0.05 / 4)$ ). Males appeared to mate randomly with respect to $\mathrm{MHC}$ amino-acid divergence $(P=0.87)$, MHC heterozygosity $(P=0.86)$ and genetic relatedness $(P=0.075$; Figure 4$)$. There was also no relationship between male phenotype and MLH or MHC 

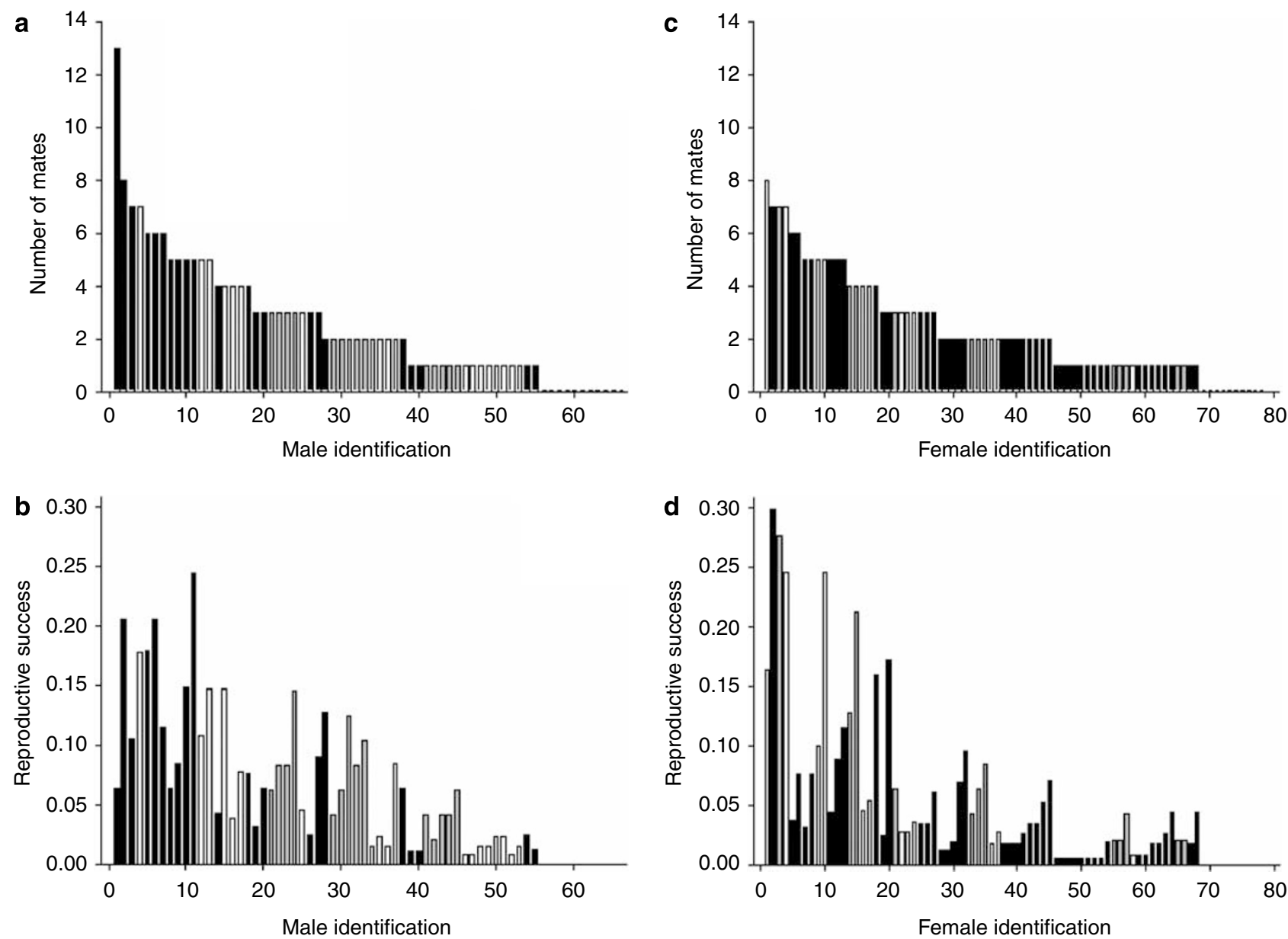

Figure 1 Summary of mating and reproductive success in Chinook salmon (Oncorhynchus tshawytscha). Data represent number of mates for males (a) or females (c), and reproductive success for males (b) or females (d). Male and female identification is based on rank order for number of mates (highest to lowest). The same identification numbers are used for the two reproductive success panels. Reproductive success was calculated within each channel and is expressed as a proportion of offspring analysed from each channel. Black bars denote the 2:1 female:male sex ratio, gray bars denote 1:1 sex ratio and open bars denote 1:2 sex ratio.

divergence $(P>0.08$ for each). Finally, there was no relationship between $\mathrm{MLH}, \mathrm{MHC}$ heterozygosity or MHC amino-acid divergence and the number of mates for either males or females ( $P>0.32$ for each).

\section{Discussion}

We used experimental spawning channels to investigate mate choice and reproductive success in Chinook salmon. Our study is among the first to demonstrate sex-specific mate choice for amino-acid divergence at the MHC class IIB in salmonids. We found that females but not males produced offspring that, on average, had MHC class IIB homologues that were more diverged at the amino-acid sequence of the peptide-binding region than would be expected by random mating. This pattern is unlikely to be explained by MHC-dependent survivorship of the offspring because we did not find a similar relationship in males. Female mate choice is well documented in salmon (Foote, 1989; Berejikian et al., 2000) and we have also directly observed aggressive acts by female Chinook salmon such as charging at individual males shortly before oviposition (SR Garner). Conversely, few studies on any organism have shown male mate choice for MHC with a notable exception from mice (Yamazaki et al., 1976; for a review see; Jordan and Bruford, 1998). The non-random pattern also cannot be explained by maternal effects because female reproductive success was not linked to a female's own MHC divergence but instead to the expected divergence in her offspring based on the male or males she mated with. Neither sex in our study appeared to select mates based on genetic relatedness, which suggests that the mate choice for MHC divergence is independent of genome-wide diversity and inbreeding avoidance. However, some caution is warranted when interpreting our relatedness estimates because they are based on only seven loci, which may not provide accurate estimates of genome-wide relatedness (Koskinen et al., 2004).

Amino-acid divergence at the peptide-binding region of the MHC class IIB may be more important for parasite resistance than heterozygosity. Amino-acid divergence corresponds to the number of amino acids that differ between homologues (Landry et al., 2001). It should be more important than heterozygosity for fitness effects when increased divergence enables individuals to recognize a broader array of pathogens. For example, a heterozygous individual may be more limited in the diversity of pathogens that can be recognized when 

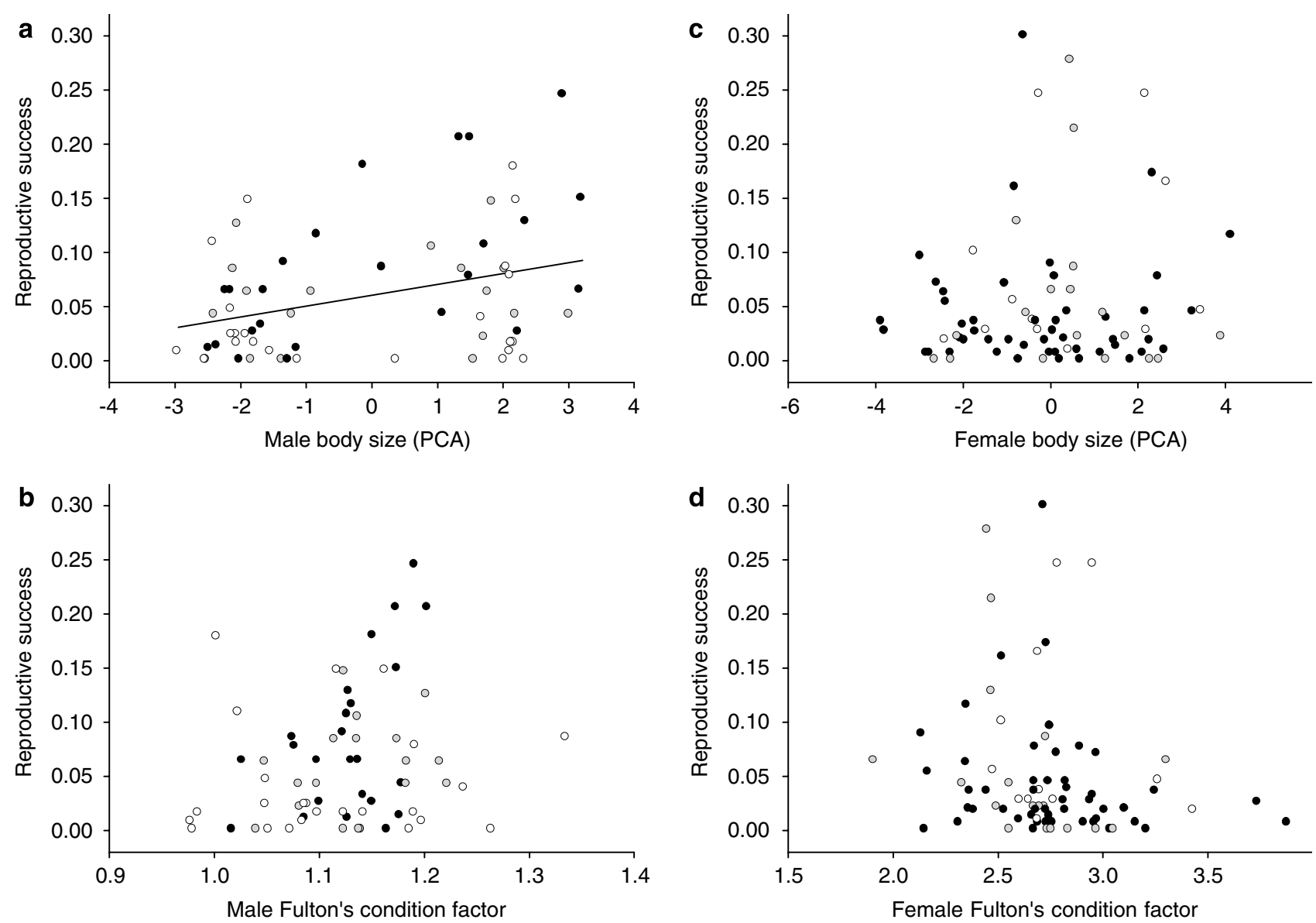

Figure 2 Summary of phenotypic correlations with reproductive success in Chinook salmon (Oncorhynchus tshawytscha). Phenotypic data consist of (a) male body size, (b) male Fulton's condition factor $\left(\mathrm{g} \mathrm{cm}^{-3} \times 10^{-2}\right)$, (c) female body size and (d) female Fulton's condition factor $\left(\mathrm{g} \mathrm{cm}^{-3} \times 10^{-2}\right)$. Body size is expressed as the first principle components axis of mass, total length, height and caudal peduncle depth. The line is from the only significant linear regression and has the equation: reproductive success $=0.061+0.010 \times$ body size $(\mathrm{PCA})\left(r^{2}=0.11, n=66\right.$, $P=0.006$ ). Reproductive success was calculated within each channel and is expressed as a proportion of offspring analyzed from each channel. Black dots denote the 2:1 female:male sex ratio, gray dots denote 1:1 sex ratio and open dots denote 1:2 sex ratio.

the two homologues have similar peptide-binding regions than when the regions differ more significantly (Wakeland et al., 1990). Such an idea is consistent with data implicating pathogen specificity of the peptidebinding region (Hill et al., 1991; Langefors et al., 2001; Arkush et al., 2002; Kurtz et al., 2006). Here we found that females mated non-randomly with respect to amino-acid divergence but not heterozygosity. These results mirror those in Atlantic salmon, in which Landry et al. (2001) found evidence of non-random mating for amino-acid divergence but no significant relationship with heterozygosity. To our knowledge, a preference for amino-acid divergence, as opposed to simply MHC heterozygosity, has been investigated in only two other organisms consisting of a rat (Hypogeomys antimena) and lekking bird (Gallinago media), but neither study found any evidence for MHC-based mate choice (Ekblom et al., 2004; Sommer, 2005). Thus, it remains unclear as to the relative importance of amino-acid divergence versus heterozygosity in governing MHC-based mate choice decisions.

Several researchers have postulated that selection should favour an optimal number of alleles at the MHC (Kurtz et al., 2004; Bonneaud et al., 2006; Forsberg et al., 2007). An optimal number may result from a tradeoff between selection for recognition of a broad array of pathogens (Doherty and Zinkernagel, 1975; Wakeland et al., 1990) and selection to minimize the loss of T-cell clones due to auto-immune induction (Nowak et al., 1992). Optimal allele number may be important in species with many copies of MHC loci such as the three-spined stickleback and house sparrow (Passer domesticus), where individuals can have between 8 and 12 alleles (Kurtz et al., 2004; Bonneaud et al., 2006). Conversely, optimal allele number is irrelevant for species that have only a single copy of an MHC locus (because they can have only one or two different alleles), but optimal amino-acid divergence may be important. For example, in the brown trout, which has only one copy of the MHC class IIB gene, Forsberg et al. (2007) argued that females selected mates to optimize aminoacid divergence of their offspring. Here we found that Chinook salmon females selected mates that produced offspring with a mean divergence of 3.3 amino acids, whereas the expected maximum was 5.0. Thus, it is conceivable that females were optimizing divergence in their offspring. On the other hand, it seems unlikely that the degree of divergence between two alleles could lead to the postulated auto-immune induction. Thus, the mechanism driving mate choice for optimal divergence would be different than that driving mate choice for optimal allele number. 

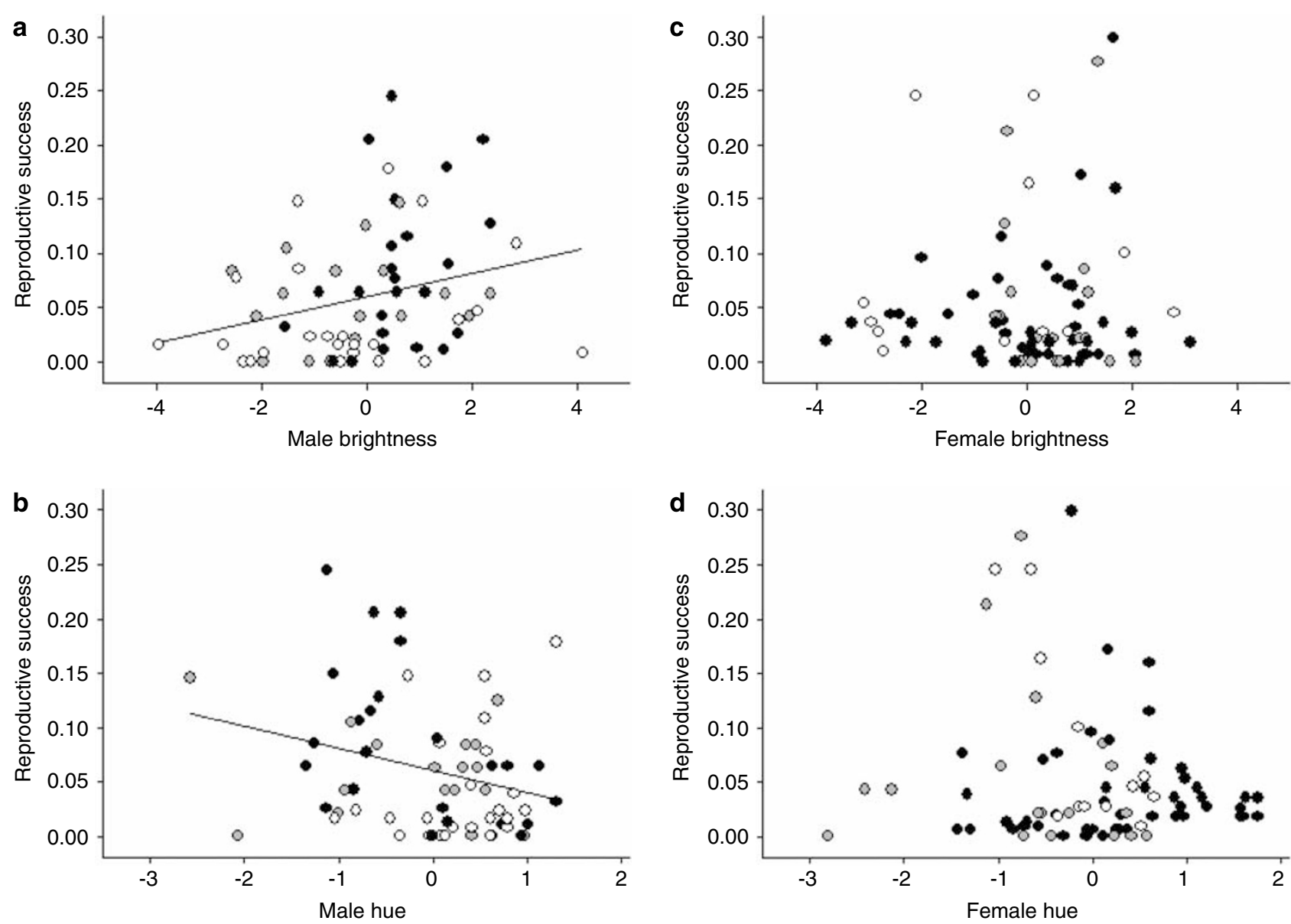

Figure 3 Summary of correlations between integument coloration and reproductive success in Chinook salmon (Oncorhynchus tshawytscha). Coloration data consist of (a) male brightness, (b) male hue, (c) female brightness and (d) female hue. Brightness and hue were extracted from principle components analysis of coloration. Negative hue values represent a green/blue coloration and positive hue values represent a red coloration. The two lines are from significant linear regressions and have the equations: reproductive success $=0.061+0.011 \times$ brightness $\left(r^{2}=0.07, n=66, P=0.030\right)$ and reproductive success $=0.061-0.020 \times$ hue $\left(r^{2}=0.07, n=66, P=0.027\right)$. Reproductive success was calculated within each channel and is expressed as a proportion of offspring analyzed from each channel. Black dots denote the 2:1 female:male sex ratio, gray dots denote 1:1 sex ratio and open dots denote 1:2 sex ratio.

In addition to partitioning variation in reproductive success to MHC genotype, we also examined several potential phenotypic correlates. In males, we found that individuals that were larger and brighter (and perhaps with a greater green/blue hue) had higher reproductive success. These results are consistent with data from other salmonids including, for example, coho salmon (O. kisutch), where larger males participated in more spawnings, obtained better positions within spawning hierarchies and fertilized a greater proportion of eggs (Fleming and Gross, 1994). Skin brightness may be an indication of male dominance as has been demonstrated in several salmonids (Abbott et al., 1985; O'Connor et al., 1999; Höglund et al., 2000) as well as other animals (Siefferman and Hill, 2005; Stapley and Whiting, 2006). Although the effect we observed with hue was not independent of brightness (and body size), it was surprising that males with more green/blue and less red had higher reproductive success. Studies of other animals including fish have identified preferences for males with more intense carotenoid displays (Milinski and Bakker, 1990; Hill, 1991; Endler and Houde, 1995) and it is more likely that the red hue is linked to these displays (McGraw, 2006). However, the mechanism
Table 2 Multiple linear regression analysis of reproductive success in Chinook salmon (Oncorhynchus tshawytscha)

\begin{tabular}{lccr}
\hline Variable & $F$ & d.f. & \multicolumn{1}{c}{$P$} \\
\hline Males & & & \\
$\quad$ Body size & 10.2 & 1,61 & $<0.01$ \\
Condition & 1.27 & 1,61 & 0.26 \\
Brightness & 14.3 & 1,61 & $<0.01$ \\
Hue & 0.18 & 1,61 & 0.67 \\
& & & \\
Females & & 1,73 & 0.55 \\
$\quad$ Body size & 0.36 & 1,73 & 0.18 \\
Condition & 1.87 & 1,73 & 0.55 \\
Brightness & 0.36 & 1,73 & 0.34 \\
Hue & 0.92 & & \\
\hline
\end{tabular}

Abbreviation: d.f., degrees of freedom.

Independent variables consist of body size, Fulton's condition factor and integument brightness and hue.

underlying green/blue colour in Chinook salmon is not yet known and it is conceivable that it is linked to carotenoids and signals male dominance or quality. It is unlikely that this relationship with colour was an artefact of the XX males we used because there is no evidence in salmon that colour is Y-chromosome linked unlike 

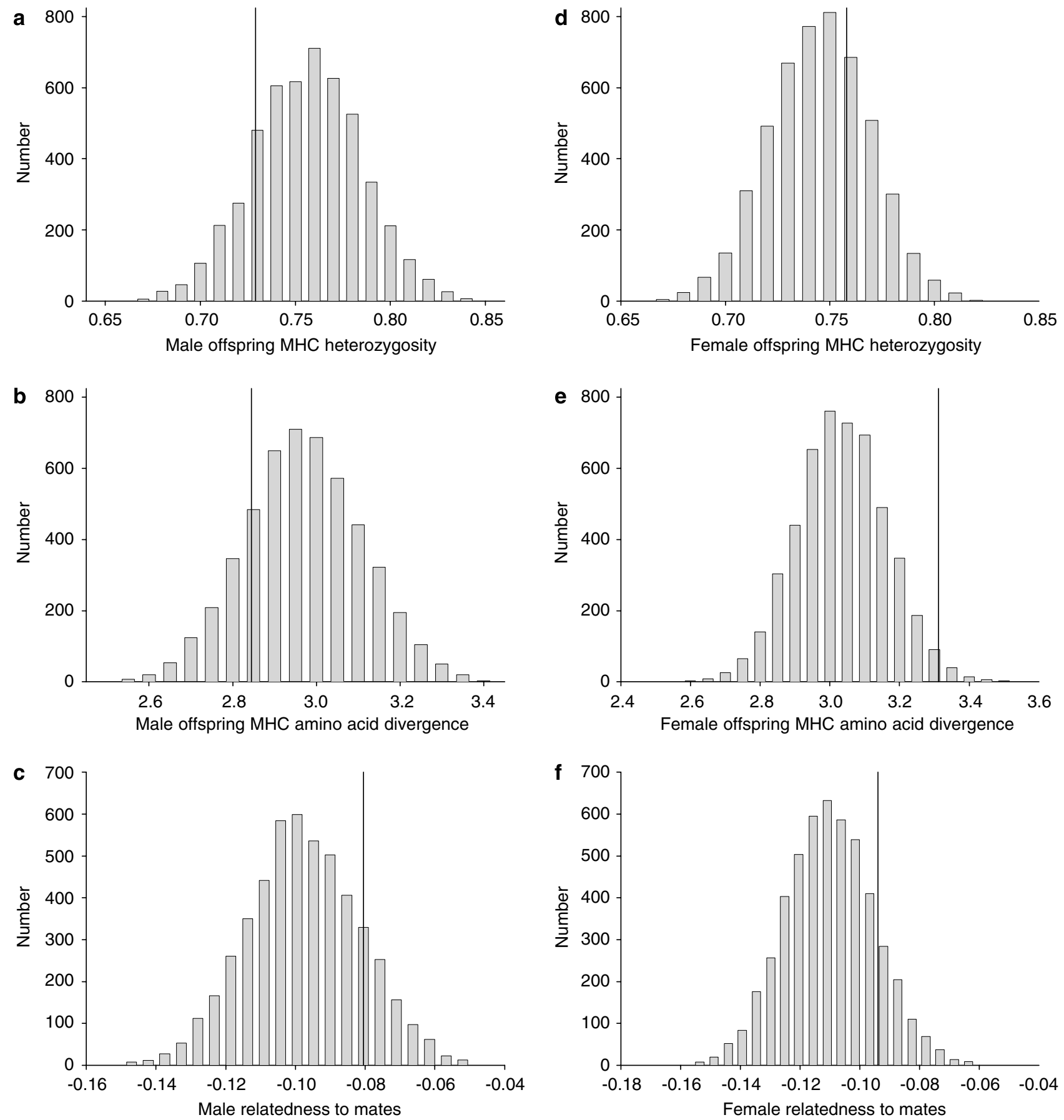

Figure 4 Summary of the Monte Carlo simulations for tests of non-random mating in Chinook salmon (Oncorhynchus tshawytscha). Data represent the distributions of 5000 simulations for the expected value under random mating for (a) male offspring major histocompatibility complex (MHC) heterozygosity, (b) male offspring MHC amino-acid divergence, (c) male genetic relatedness to mates, (d) female offspring MHC heterozygosity, (e) female offspring MHC amino-acid divergence and (f) female genetic relatedness to mates. The vertical line in each panel denotes the observed value.

some other fishes (for example, guppy, Poecilia reticulata: Brooks and Endler, 2001; Southern platyfish, Xiphophorus maculatus: Basolo, 2006). Chinook salmon have limited sexual dimorphism and similar coloration in both sexes (Healey, 1991), which suggest that a strong sex-linked genetic effect on coloration is unlikely. Indeed, a study of sockeye salmon has demonstrated heritable differences in pigmentation with similar effects on both sexes, which argues against sex-linked control of pigmentation (Craig and Foote, 2001). Nevertheless, in salmonids, as in other animals, there appears to be selection in males for larger body size and for bright integument coloration.

Female phenotype on the other hand may have a variable contribution to reproductive success in salmonids. We found no effect of female phenotype on reproductive success. Consistent with our results, in steelhead trout (O. mykiss), there was no relationship between female body size and reproductive success (McLean et al., 2004). In pink salmon (O. keta), a study across 2 years revealed no effect of female body size on 
reproductive success in the first year but in the second year, females of intermediate size had the highest reproductive success (Dickerson et al., 2005). In contrast to these results, in coho salmon, larger females had higher reproductive success than smaller females (van den Berghe and Gross, 1989; Fleming and Gross, 1994). The increased success of coho salmon females was attributed in part to larger females accessing more spawning sites and initiating spawning sooner than smaller females. We did not directly monitor spawning activity in our study, so we do not know if either of these variables was important. It is unlikely, however, that spawning density can explain the different results between our study and the coho salmon study as the densities were similar across the two studies (our study: $2.1-4.38 \mathrm{~m}^{2}$ per female; coho study: $1.25-5.0 \mathrm{~m}^{2}$ per female). Thus, it remains unclear whether or not body size is important in reproductive success of female salmonids.

Perhaps surprisingly we found no effect of the operational sex ratio on the intensity of sexual selection. Theory suggests that biased sex ratios should increase the opportunity for sexual selection (Emlen and Oring, 1977). Thus, for example, we may have expected the male-biased sex ratio to increase the selection on male body size. Indeed, male-biased sex ratios in spider mites (Tetranychus urticae) are associated with higher frequencies of agonistic interactions among males, and larger males are better able to resist interference by smaller males during mating (Enders, 1993). Furthermore, in coho salmon, Fleming and Gross (1994) estimated that competition led to a 52-fold increase in selection on male body size. However, among their three competition experiments, the authors found that selection on male body size was actually lower when spawning sites were limited (effectively a male-biased sex ratio) than when spawning sites were less limited. Thus, selection on body size may be quite complex over the range of competition intensities (also see Hamon and Foote, 2005) and we may not have detected its effect over the range studied in our experiment.

In summary, we have detailed phenotypic and genotypic correlates of reproductive success in Chinook salmon. We found that sexual selection favours increased body size and aspects of integument coloration in males, but not females. Non-random mating by females led to increased divergence at the MHC class IIB locus and appeared to be independent of genome-wide divergence as measured by genetic relatedness. MHC amino-acid divergence, however, was not related to the phenotypic characteristics we addressed outside of perhaps a positive relationship between female brightness and divergence. Nevertheless, our data suggest that researchers should consider divergence in addition to disassortative mating for heterozygosity at the MHC.

\section{Acknowledgements}

We thank Jennifer Bronnenhuber, Grace Cho, Richard Bergeron, Kieran Jones and Anne Heath for assistance, and two anonymous reviewers for their helpful comments. The experiments conformed to animal care guidelines outlined by the Canadian Council on Animal Care. This work was supported by a Natural Sciences and Engineering Research Council of Canada Strategic Project grant.

\section{References}

Abbott JC, Dunbrack RL, Orr CD (1985). The interaction of size and experience in dominance relationships of juvenile steelhead trout (Salmo gairdneri). Behaviour 92: 241-253.

Andersson MB (1994). Sexual Selection. Princeton University Press: Princeton.

Arkush KD, Giese AR, Mendonca HL, McBride AM, Marty GD, Hedrick PW (2002). Resistance to three pathogens in the endangered winter-run Chinook salmon (Oncorhynchus tshawytscha): effects of inbreeding and major histocompatibility complex genotypes. Can J Fisheries Aquat Sci 59: 966-975.

Basolo AL (2006). Genetic linkage and color polymorphism in the Southern platyfish (Xiphophorus maculatus): a model system for studies of color pattern evolution. Zebrafish 3: 65-83.

Beacham TD, Murray CB (1993). Fecundity and egg size variation in North American Pacific salmon (Oncorhynchus). J Fish Biol 42: 485-508.

Berejikian BA, Tezak EP, LaRae AL (2000). Female mate choice and spawning behaviour of Chinook salmon under experimental conditions. J Fish Biol 57: 647-661.

Bernatchez L, Landry C (2003). MHC studies in nonmodel vertebrates: what have we learned about natural selection in 15 years? J Evol Biol 16: 363-377.

Bonneaud C, Chastel O, Federici P, Westerdahl H, Sorci G (2006). Complex MHC-based mate choice in a wild passerine. Proc R Soc B Biol Sci 273: 1111-1116.

Brooks R, Endler JA (2001). Direct and indirect sexual selection and quantitative genetics of male traits in guppies (Poecilia reticulata). Evolution 55: 1002-1015.

Brown JH, Jardetzky T, Saper MA, Samraoui B, Bjorkman PJ, Wiley DC (1988). A hypothetical model of the foreign antigen-binding site of class II histocompatibility molecules. Nature 332: 845-850.

Clutton-Brock TH (1982). The functions of antlers. Behaviour 79 . 108-125.

Craig JK, Foote CJ (2001). Countergradient variation and secondary sexual color: phenotypic convergence promotes genetic divergence in carotenoid use between sympatric anadromous and nonanadromous morphs of sockeye salmon (Oncorhynchus nerka). Evolution 55: 380-391.

Dickerson BR, Brinck KW, Willson MF, Bentzen P, Quinn TP (2005). Relative importance of salmon body size and arrival time at breeding grounds to reproductive success. Ecology 86: 347-352.

Dickerson BR, Quinn TP, Willson MF (2002). Body size, arrival date, and reproductive success of pink salmon, Oncorhynchus gorbuscha. Ethol Ecol Evol 14: 29-44.

Docker MF, Heath DD (2002). PCR-based markers detect genetic variation at growth and immune function-related loci in Chinook salmon (Oncorhynchus tshawytscha). Mol Ecol Notes 2: 606-609.

Doherty PC, Zinkernagel RM (1975). Enhanced immunological surveillance in mice heterozygous at the $\mathrm{H}-2$ gene complex. Nature 256: 50-52.

Ekblom R, Sæther SA, Grahn M, Fiske P, Kålås JA, Höglund J (2004). Major histocompatibility complex variation and mate choice in a lekking bird, the great snipe (Gallinago media). Mol Ecol 13: 3821-3828.

Emlen ST, Oring LW (1977). Ecology, sexual selection, and the evolution of mating systems. Science 197: 215-223.

Enders MM (1993). The effect of male size and operational sex ratio on male mating success in the common spider mite, Tetranychus urticae Koch (Acari: Tetranychidae). Anim Behav 46: 835-846.

Endler JA, Houde AE (1995). Geographic variation in female preferences for male traits in Poecilia reticulata. Evolution 49: 456-468.

Fitzpatrick JL, Henry JC, Liley NR, Devlin RH (2005). Sperm characteristics and fertilization success of masculinized coho salmon (Oncorhynchus kisutch). Aquaculture 249: 459-468.

Fleming IA (1998). Pattern and variability in the breeding system of Atlantic salmon (Salmo salar), with comparisons to other salmonids. Can J Fisheries Aquat Sci 55 (Suppl 1): 59-76. 
Fleming IA, Gross MR (1993). Breeding success of hatchery and wild coho salmon (Oncorhynchus kisutch) in competition. Ecol Appl 3: 230-245.

Fleming IA, Gross MR (1994). Breeding competition in a Pacific salmon (coho: Oncorhynchus kisutch): measures of natural and sexual selection. Evolution 48: 637-657.

Fleming IA, Hindar K, Mjolnerod IB, Jonsson B, Balstad T, Lamberg A (2000). Lifetime success and interactions of farm salmon invading a native population. Proc $R$ Soc Lond B Biol Sci 267: 1517-1523.

Foote CJ (1989). Female mate preference in Pacific salmon. Anim Behav 38: 721-723.

Foote CJ (1990). An experimental comparison of male and female spawning territoriality in a Pacific salmon. Behaviour 115: 283-314.

Forsberg LA, Dannewitz J, Petersson E, Grahn M (2007). Influence of genetic dissimilarity in the reproductive success and mate choice of brown trout-females fishing for optimal MHC dissimilarity. J Evol Biol 20: 1859-1869.

Freeman-Gallant CR, Meguerdichian M, Wheelwright NT, Sollecito SV (2003). Social pairing and female mating fidelity predicted by restriction fragment length polymorphism similarity at the major histocompatibility complex in a songbird. Mol Ecol 12: 3077-3083.

Grimholt U, Larsen S, Nordmo R, Midtlyng P, Kjoeglum S, Storset A et al. (2003). MHC polymorphism and disease resistance in Atlantic salmon (Salmo salar); facing pathogens with single expressed major histocompatibility class I and class II loci. Immunogenetics 55: 210-219.

Hamon TR, Foote CJ (2005). Concurrent natural and sexual selection in wild male sockeye salmon, Oncorhynchus nerka. Evolution 59: 1104-1118.

Hansen JD, Strassburger P, Thorgaard GH, Young WP, Du Pasquier L (1999). Expression, linkage, and polymorphism of MHC-related genes in rainbow trout, Oncorhynchus mykiss. I Immunol 163: 774-786.

Healey MC (1991). Life history of Chinook Salmon. In: Groot C, Margolis L (eds). Pacific Salmon Life Histories. University of British Columbia Press: Vancouver, pp 311-394.

Heath DD, Heath JW, Bryden CA, Johnson RM, Fox CW (2003). Rapid evolution of egg size in captive salmon. Science 299: $1738-1740$.

Heath DD, Rankin L, Bryden CA, Heath JW, Shrimpton JM (2002). Heritability and Y-chromosome influence in the jack male life history of Chinook salmon (Oncorhynchus tshawytscha). Heredity 89: 311-317.

Hill AVS, Allsopp CEM, Kwiatkowski D, Anstey NM, Twumasi P, Rowe PA et al. (1991). Common West African HLA antigens are associated with protection from severe malaria. Nature 352: 595-600.

Hill GE (1991). Plumage coloration is a sexually selected indicator of male quality. Nature 350: 337-339.

Höglund E, Balm PHM, Winberg S (2000). Skin darkening, a potential social signal in subordinate Arctic charr (Salvelinus alpinus): The regulatory role of brain monoamines and proopiomelanocortin-derived peptides. J Exp Biol 203: 1711-1721.

Janeway CA, Travers P, Walport M, Capra JD (1999). Immunobiology: The Immune System in Health and Disease, 4th edn. Current Biology Publications: London, UK.

Jordan WC, Bruford MW (1998). New perspectives on mate choice and the MHC. Heredity 81: 127-133.

Kalinowski ST, Taper ML, Marshall TC (2007). Revising how the computer program CERVUS accommodates genotyping error increases success in paternity assignment. Mol Ecol 16: 1099-1106.

Kim TJ, Parker KM, Hedrick PW (1999). Major histocompatibility complex differentiation in Sacramento River Chinook salmon. Genetics 151: 1115-1122.

Klump GM, Gerhardt HC (1987). Use of non-arbitrary acoustic criteria in mate choice by female gray tree frogs. Nature $\mathbf{3 2 6}$ 286-288.

Koskinen MT, Hirvonen H, Landry PA, Primmer CR (2004). The benefits of increasing the number of microsatellites utilized in genetic population studies: an empirical perspective. Hereditas 141: 61-67.

Kurtz J, Kalbe M, Aeschlimann PB, Häberli MA, Wegner KM, Reusch TBH et al. (2004). Major histocompatibility complex diversity influences parasite resistance and innate immunity in sticklebacks. Proc R Soc Lond B Biol Sci 271: 197-204.

Kurtz J, Wegner KM, Kalbe M, Reusch TBH, Schaschl H, Hasselquist D et al. (2006). MHC genes and oxidative stress in sticklebacks: an immuno-ecological approach. Proc $R$ Soc $B$ Biol Sci 273: 1407-1414.

Landry C, Garant D, Duchesne P, Bernatchez L (2001). Good genes as heterozygosity: the major histocompatibility complex and mate choice in Atlantic salmon (Salmo salar). Proc $R$ Soc Lond B Biol Sci 268: 1279-1285.

Langefors A, Lohm J, Grahn M, Andersen O, von Schantz T (2001). Association between major histocompatibility complex class IIB alleles and resistance to Aeromonas salmonicida in Atlantic salmon. Proc R Soc Lond B Biol Sci 268: 479-485.

Leinders-Zufall T, Brennan P, Widmayer P, Chandramani P, Maul-Pavicic A, Jäger M et al. (2004). MHC class I peptides as chemosensory signals in the vomeronasal organ. Science 306: 1033-1037.

Lohm J, Grahn M, Langefors A, Andersen O, Storset A, von Schantz T (2002). Experimental evidence for major histocompatibility complex-allele-specific resistance to a bacterial infection. Proc R Soc Lond B Biol Sci 269: 2029-2033.

Manly BFJ (1997). Randomization, Bootstrapping and Monte Carlo Methods in Biology, 2nd edn. Chapman and Hall: London, UK.

Marshall TC, Slate J, Kruuk LEB, Pemberton JM (1998). Statistical confidence for likelihood-based paternity inference in natural populations. Mol Ecol 7: 639-655.

Mays HL, Hill GE (2004). Choosing mates: good genes versus genes that are a good fit. Trends in Ecol Evol 19: 554-559.

McGraw KJ (2006). Mechanics of carotenoid-based coloration. In: Hill GE, McGraw KJ (eds). Bird Coloration: Mechanisms and Measurements. Harvard University Press: Cambridge, MA, vol. I, pp 177-242.

McLean JE, Bentzen P, Quinn TP (2004). Does size matter? Fitness-related factors in steelhead trout determined by genetic parentage assignment. Ecology 85: 2979-2985.

Milinski M, Bakker TCM (1990). Female sticklebacks use male coloration in mate choice and hence avoid parasitized males. Nature 344: 330-333.

Miller KM, Withler RE (1996). Sequence analysis of a polymorphic MHC class II gene in Pacific salmon. Immunogenetics 43: 337-351.

Neff BD, Fu P, Gross MR (2000). Microsatellite multiplexing in fish. Trans Am Fisheries Soc 129: 584-593.

Neff BD, Pitcher TE (2005). Genetic quality and sexual selection: an integrated framework for good genes and compatible genes. Mol Ecol 14: 19-38.

Nowak MA, Tarczy-Hornoch K, Austyn JM (1992). The optimal number of major histocompatibility complex molecules in an individual. Proc Natl Acad Sci USA 89: 10896-10899.

O'Connor KI, Metcalfe NB, Taylor AC (1999). Does darkening signal submission in territorial contests between juvenile Atlantic salmon, Salmo salar? Anim Behav 58: 1269-1276.

Olsen JB, Wenburg JK, Bentzen P (1996). Semiautomated multilocus genotyping of Pacific salmon (Oncorhynchus spp.) using microsatellites. Mol Mar Biol Biotechnol 5: 259-272.

Penn DJ (2002). The scent of genetic compatibility: sexual selection and the major histocompatibility complex. Ethology 108: $1-21$.

Penn DJ, Damjanovich K, Potts WK (2002). MHC heterozygosity confers a selective advantage against multiple-strain infections. Proc Natl Acad Sci USA 99: 11260-11264.

Penn D, Potts W (1998). MHC-disassortative mating preferences reversed by cross-fostering. Proc $R$ Soc Lond B Biol Sci 265: 1299-1306.

Piferrer F (2001). Endocrine sex control strategies for the feminization of teleost fish. Aquaculture 197: 229-281. 
Pitcher TE, Neff BD (2006). MHC class IIB alleles contribute to both additive and nonadditive genetic effects on survival in Chinook salmon. Mol Ecol 15: 2357-2365.

Potts WK, Manning CJ, Wakeland EK (1991). Mating patterns in seminatural populations of mice influenced by $M H C$ genotype. Nature 352: 619-621.

Queller DC, Goodnight KF (1989). Estimating relatedness using genetic markers. Evolution 43: 258-275.

Reusch TBH, Haberli MA, Aeschlimann PB, Milinski M (2001). Female sticklebacks count alleles in a strategy of sexual selection explaining MHC polymorphism. Nature 414: 300-302.

Roberts SC, Gosling LM (2003). Genetic similarity and quality interact in mate choice decisions by female mice. Nat Genet 35: 103-106.

Seamons TR, Bentzen P, Quinn TP (2007). DNA parentage analysis reveals inter-annual variation in selection: results from 19 consecutive brood years in steelhead trout. Evol Ecol Res 9: 409-431.

Siefferman L, Hill GE (2005). UV-blue structural coloration and competition for nestboxes in male eastern bluebirds. Anim Behav 69: 67-72.

Skarstein F, Folstad I, Liljedal S, Grahn M (2005). MHC and fertilization success in the Arctic charr (Salvelinus alpinus). Behav Ecol Sociobiol 57: 374-380.

Sommer S (2005). Major histocompatibility complex and mate choice in a monogamous rodent. Behav Ecol Sociobiol 58: 181-189.

Stapley J, Whiting MJ (2006). Ultraviolet signals fighting ability in a lizard. Biol Lett 2: 169-172.

\section{Appendix 1}

Summary of the 18 amino acid sequences at the peptide binding region of the MHC class IIB locus in Chinook salmon (Oncorhynchus tshawytscha). The diagram depicts the presumed evolutionary relationship between the alleles where each dot denotes one amino acid substitution. Sequences were originally reported in Miller and
Steen RP, Quinn TP (1999). Egg burial depth by sockeye salmon (Oncorhynchus nerka): implications for survival of embryos and natural selection on female body size. Can J Zool 77: 836-841.

van den Berghe EP, Gross MR (1989). Natural selection resulting from female breeding competition in a Pacific salmon (coho: Oncorhynchus kisutch). Evolution 43: 125-140.

Villafuerte R, Negro JJ (1998). Digital imaging for colour measurement in ecological research. Ecol Lett 1: 151-154.

Wakeland EK, Boehme S, She JX, Lu CC, McIndoe RA, Cheng I et al. (1990). Ancestral polymorphisms of MHC class II genes: divergent allele advantage. Immunol Res 9: 115-122.

Welch AM, Semlitsch RD, Gerhardt HC (1998). Call duration as an indicator of genetic quality in male gray tree frogs. Science 280: 1928-1930.

Williamson KS, Cordes JF, May B (2002). Characterization of microsatellite loci in Chinook salmon (Oncorhynchus tshawytscha) and cross-species amplification in other salmonids. Mol Ecol Notes 2: 17-19.

Wolf K (1988). Infectious hematopoietic necrosis virus. In: Wolf $\mathrm{K}$ (ed) Fish Viruses and Fish Viral Diseases. Cornell University Press: Ithaca, New York, pp 83-114.

Yamazaki K, Boyse EA, Mike V, Thaler HT, Mathieson BJ, Abbott J et al. (1976). Control of mating preferences in mice by genes in the major histocompatibility complex. J Exp Med 144: 1324-1335.

Ziegler A, Kentenich H, Uchanska-Ziegier B (2005). Female choice and the MHC. Trends Immunol 26: 496-502.

Withler (1996) (Onts Ha, Tj; Wh), Kim et al. (1999) (Onts 1f1, wr1, wr2, wr3), Docker and Heath (2002) (Onts 1, 1a, 1b, 2, 2a, 3), and Pitcher and Neff (2006) (Onts Cr1, Cr2, Cr3). Alleles that did not differ in protein sequence are separated with a forward slash, and Genbank accession numbers are provided below all alleles. Bolded names indicate alleles found in the YIAL population.

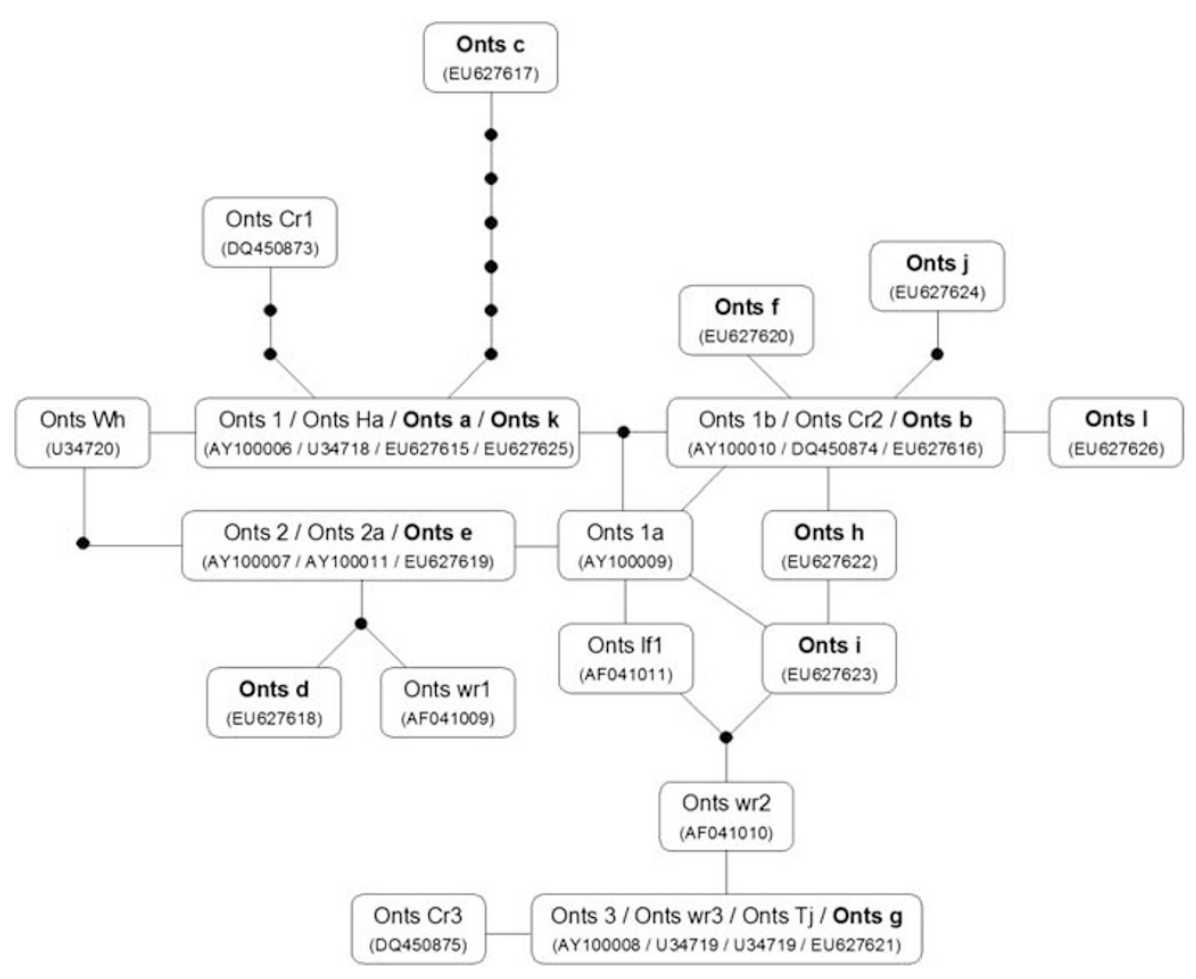

